\title{
El sabueso medieval. Fuentes e iconografía desde su origen hasta los tratados cinegéticos del siglo XIV
}

\author{
Carlos Espí Forcén \\ Universidad de Murcia \\ espforce@um.es
}

RESUMEN: El sabueso es un perro de rastro utilizado por los pueblos celtas desde la Antigüedad. No hemos conservado apenas referencias documentales o artísticas de sabuesos durante la Alta Edad Media. A partir del siglo XIII podemos tener una idea clara de la morfología y utilidad de los sabuesos a través de las enciclopedias, tratados de caza e imágenes artísticas. El arte y los manuscritos ilustrados de la Baja Edad Media demuestran que fue el perro más preciado por reyes y nobles en virtud de sus cualidades cinegéticas, hasta el punto en que se convirtió en el protagonista de la montería medieval.

PALABRAS CLAVE: Sabueso; Caza; Montería; Manuscrito; Arte medieval.

\section{The Medieval Scenthound. Sources and Iconography from its Origens to the Hunting Treatises of the $14^{\text {th }}$ Century}

ABSTRACT: A scenthound is hunting dog used by Celtic tribes since Antiquity. Very few written or artistic references to hounds have been preserved in the High Middle Ages. From the $13^{\text {th }}$ century onwards encyclopaedias, hunting treatises and artistic images offer a clear portrait of the morphology and use of scenthounds. Late medieval art and illuminated manuscripts show that scenthounds were the dogs most valued by kings and noblemen for their hunting skills. Thus, these hounds played an extremely relevant role in the medieval art of the chase.

KEYWORDS: Hound; Hunting; Chase; Manuscript; Medieval art.

Recibido: 28 de febrero de 2019 / Aceptado: 26 de abril de 2019.

Los perros que dan más satisfacción son los sabuesos [...] [el sabueso] debe cazar todo el día diciendo y alardeando en su lenguaje, profiriendo villanías contra el animal que quiere capturar. Para mí lo tengo más que a cualquier otro tipo de perros, pues poseen, porque tienen, así me lo parece, más cualidades que ningún otro animal’1. Gastón Fébus, Livre de la chasse (1387-1389).

De este poético modo expresó Gastón Fébus, III Conde de Foix, su amor por los sabuesos en el último cuarto del siglo XIV. Lo que más apreciaba de ellos fue la cualidad que mejor los define: los aullidos y ladridos (latidos)² que entonan en el monte cuando siguen el rastro de las piezas o las persiguen tras el levante. Un sabueso es un tipo de perro de caza especializado en seguir el rastro que los animales dejan por tierra hasta hallar el lugar en el que se encuentran en el bosque. Fueron utilizados en las monterías medievales para localizar a los animales y hacerlos huir. En este momento se producía una persecución por parte de la jauría de sabuesos como por cazadores a caballo hasta atrapar al animal y darle muerte con flechas, lanzas o espadas.

Durante la Edad Media la montería fue privilegio de las clases más pudientes puesto que eran necesarios una gran cantidad de recursos no disponibles para la mayor parte de los estamentos sociales. Nobles y reyes se reservaron el derecho

Cómo citar este artículo: ESPÍ FORCÉN, Carlos, «El sabueso medieval. Fuentes e iconografía desde su origen hasta los tratados cinegéticos del siglo XIV», Boletín de Arte-UMA, n. ${ }^{\circ}$ 40, Departamento de Historia del Arte, Universidad de Málaga, 2019, pp. 123-133, ISSN: 0211-8483, e-ISSN: 2695-415X, DOI: http://dx.doi.org/10.24310/ BoLArte.2019.v0i40.5699 
a cazar las piezas de mayor valor en los mejores territorios a su alcance y tenían la potestad de conceder permisos a los habitantes de sus dominios (Bord y Mugg, 2018: 17-26). La montería requería la existencia de un grupo de cazadores a servicio del señor, tanto para el cuidado, cría o entrenamiento de perros y caballos, como para acompañarle en las cacerías. Cuando se decidía cazar un bosque previamente estudiado por parte de los monteros, se partía a primera hora de la mañana con sabuesos atraillados para conocer el rastro de los animales. Con ello los monteros lograban conocer los puntos donde habrían de soltar las jaurías, que seguirían los rastros de los animales e iniciarían la persecución. Les acompañaban monteros a caballo con lanzas y cuernos para animar a los canes. Las piezas más valoradas fueron corzos, ciervos, jabalíes y osos. Tras la persecución de los sabuesos, los cazadores empleaban perros de agarre (alanos) ${ }^{3}$ para inmovilizar a las presas. En ocasiones, la estocada final al animal quedaba reservada para el noble o señor, que demostraba de este modo su valor frente a sus súbditos. Por último, vendría el despiece del animal, los lomos y las mejores piezas se reservaban para el noble, mientras que las vísceras se otorgaban a los canes ${ }^{4}$.

Tal suntuosidad fue inaccesible para la gente común, cuyos métodos de caza consistían en modestas trampas apenas mencionadas en los tratados de caza medievales (Cummins, 1988: 234-248). Por el contrario, el boato de la montería nobiliaria exigía una buena jauría de sabuesos latiendo rastros en el bosque en bucólica sinfonía con el sonido de cuernos insuflados por monteros y jinetes. Los orígenes del sabueso se remontan a la Antigüedad, pero su prestigio fue en aumento a lo largo de los siglos hasta llegar a enamorar a los más célebres cazadores de la Baja Edad Media como fue el caso del III Conde de Foix.

\section{Un origen celta}

El característico sabueso de oreja caída, amplio belfo y ojos tristones fue en gran parte desconocido en el mundo antiguo. Un repaso por la cerámica griega y el mosaico romano nos hará conscientes de que griegos y romanos optaron por el uso de un perro de caza mediterráneo de orejas erguidas y hocico afilado, cuya virtud venatoria residía tanto en la vista, como en el olfato ${ }^{5}$. El tratado de caza más célebre de la antigua Grecia describe a los perros de caza de forma similar a como los vemos retratados en la cerámica griega. A principios del siglo IV a. C. retrata Jenofonte a los buenos perros de caza en su Cinegética como canes con «cabeza ligera [...] orejas pequeñas, delgadas y con poco pelo por detrás». A pesar de la divergencia morfológica entre los perros de caza griegos y los sabuesos medievales, la descripción que hace Jenofonte de la forma de cazar de los perros griegos se parece bastante a la de los sabuesos, pues afirma que siguen «la pista alejándose rápidamente de los senderos batidos, sonriendo cuando topan con las huellas y agachando las orejas y luego mueven continuamente los ojos y agitan la cola y todos a la vez avanzan hacia los cados describiendo muchos círculos» (Jenofonte, 1965: 21-22).

Resulta difícil saber si los perros descritos por Jenofonte fueron sabuesos o no, lo que sí que sabemos es que existió otro tipo de perro de caza en la Antigüedad mucho más parecido al sabueso medieval. Este perro fue descrito por primera vez en el siglo II de nuestra era por el historiador griego Flavio Arriano en una obra homónima en honor al célebre tratado de Jenofonte. Arriano comienza su Cinegética citando a Jenofonte y señalando que «en su opinión, dicho tratado no menciona las razas celtas de perros, no por falta de escrupulosidad, sino por ignorancia», ya que fueron desconocidas para los griegos de su época. Arriano se dispone por lo tanto a enriquecer la obra de Jenofonte con la descripción de dos tipos de perros de caza celtas: un tipo de galgo (vertragus), alabado por su capacidad para atrapar liebres de forma natural, y los perros llamados segusiae. En opinión de Arriano, los segundos tomarían su nombre de los celtas segusiavos de la Galia Lugdunense, tribu que los habría criado por primera vez. El autor advierte que el estilo de cazar de estos perros no era muy distinto del descrito por Jenofonte; pero que, sin embargo, eran mucho más feos y salvajes. Tiene tan mala opinión de ellos, que llega a afirmar que «sobre estos perros no creo que nadie sea capaz de escribir algo digno de leer». No obstante, de las pocas líneas peyorativas que dedica a estos canes celtas, deducimos que pudieron ser los antecedentes de los sabuesos medievales. Arriano escribe que «siguen el rastro con llantos y ladridos, cantando de forma similar a los [perros] carios, pero se vuelven aún más frenéticos cuando captan el rastro». El volumen de los latidos es un rasgo propio de los sabuesos que disgusta al autor; del mismo modo, Arriano arremete 


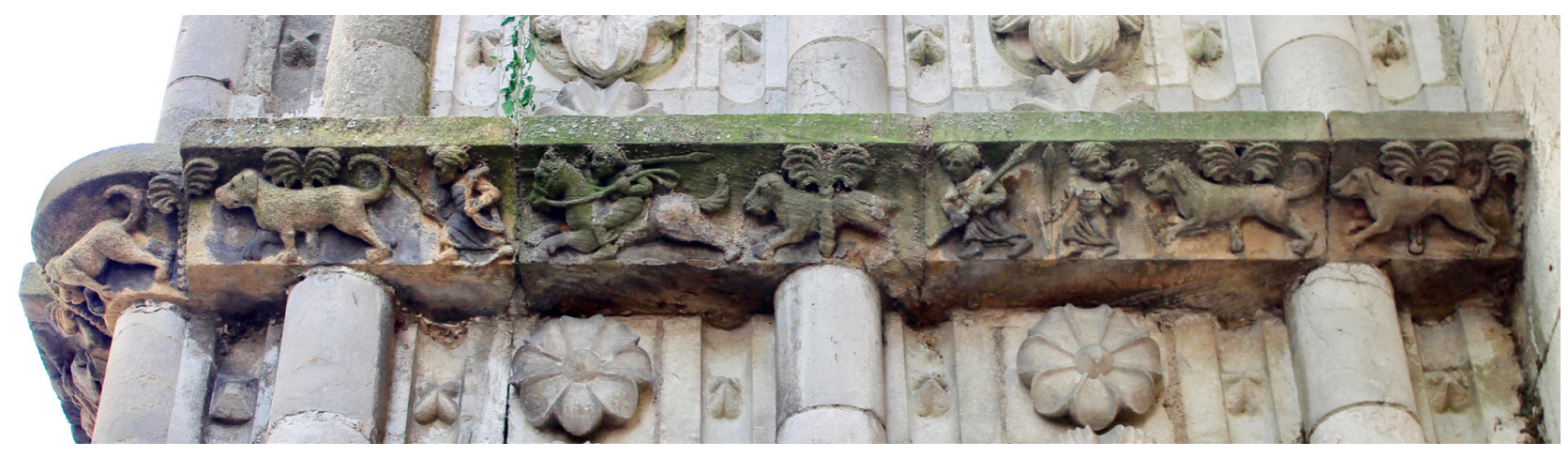

1. St. Étienne de Cahors, siglo XII, detalle del friso de la fachada septentrional

duramente contra los segusiae por su lentitud: «Es todo un logro si llegan a matar una sola liebre en la temporada de invierno, ya que le dan tanto tiempo para descansar, que sería más fácil que la capturasen por el pánico que le producen los llantos de los perros [...] pues sus voces son tristes y lamentables y aúllan cuando siguen el rastro, no de forma hostil ante el animal salvaje, sino con lamentos de compasión» (Arriano, 1999: 91-95).

Las voces tristes, aullidos, ladridos o lamentos son perfectamente compatibles con los latidos de los sabuesos cuando siguen un rastro o inician una persecución. Arriano no entendió las cualidades de los sabuesos, pues de ellos en ningún momento se puede esperar que atrapen una liebre, sino que sigan su rastro latiendo y la hagan huir del lugar en que se halle encamada. Es esta cualidad la que convertía al sabueso en el perro idóneo para levantar cualquier tipo de animal terrestre. Una prueba más del vínculo de los segusiae con los sabuesos es que de este término derive la palabra «sabueso" en castellano y «segugio» en italiano. Afortunadamente los cazadores de siglos posteriores comprendieron las virtudes de los sabuesos hasta el punto en que se convirtieron en los protagonistas de la montería medieval.

\section{Perro de oreja larga y labio caído}

A pesar de que no hayamos conservado ningún tratado de caza durante la Alta Edad Media, podemos intuir que estos sabuesos de origen celta fueron frecuentemente utilizados para seguir el rastro de animales durante la actividad cinegética. El hecho de que los pueblos germánicos apreciasen la caza del ciervo, del oso y del jabalí nos hace pensar que es muy probable que utilizasen sabuesos para localizar los rastros y perros de agarre para atrapar a los animales, tal y como se hacía durante la Baja Edad Media. Las pocas imágenes de cacerías que hemos conservado entre los siglos VI y XII no nos dan una idea clara del tipo de perro que usaron. Generalmente se corresponden a perros de agarre para poder dar muerte a una gran pieza, una escena de tinte clásico que tendrá asimismo cierto éxito en épocas posteriores ${ }^{6}$.

Una de las primeras representaciones de sabuesos cazando en el arte medieval corresponde a unos relieves de mediados del siglo XII del friso de la fachada románica de St. Étienne de Cahors (Durliat, 1979: 315-331). La representación de escenas de caza en frisos medievales es una característica propia de la marginalia medieval (Camille, 1992; Kenaan-Kedar, 1995), pero Cahors es especialmente interesante por la inclusión de sabuesos. En concreto, hay dos escenas de caza en los laterales de un friso que enmarca la portada que contiene el tímpano. El friso oeste es el que mejor se ha conservado, la lectura comienza con un montero llamando a los sabuesos con el cuerno, mientras que otros avanzan junto a varios cazadores a caballo, con arco o lanzas [1]. Sabemos que son sabuesos por el tipo de oreja larga y caída que los caracteriza frente a otros perros de caza. De hecho, la escena continúa al girar el friso con la persecución de un ciervo por parte de alanos, un cazador lo espera y se dispone a darle muerte disparando una flecha [2]. Los alanos presentan orejas de menores dimensiones (quizás incluso cortadas), un cuerpo más ligero y unas mandíbulas más potentes. Con ellas habrán de atrapar la pieza para que pueda ser abatida por los monteros. 


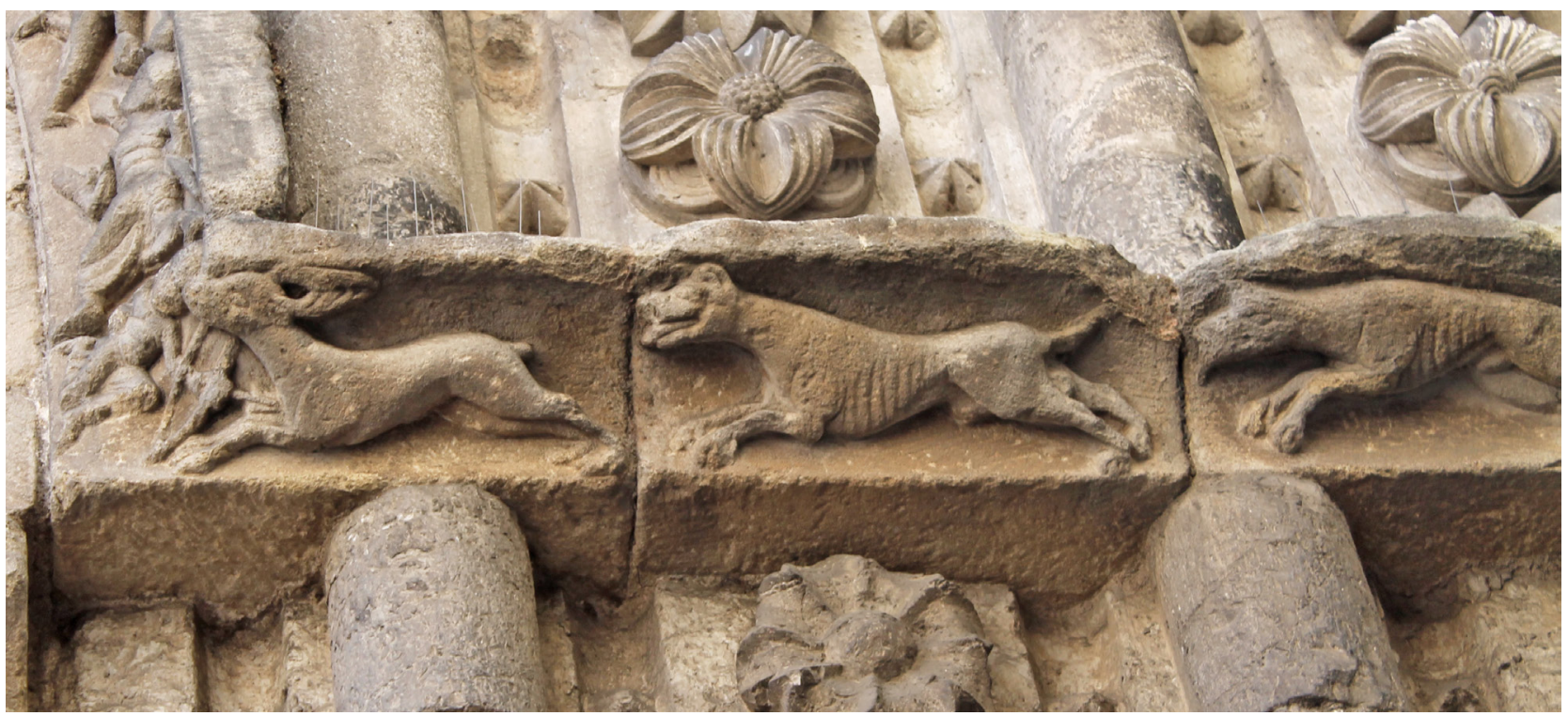

2. St. Étienne de Cahors, siglo XII, detalle del friso de la fachada septentrional

Las pocas líneas que definen a los sabuesos en la literatura medieval insistirán en las orejas amplias, largas y caídas como su rasgo más distintivo. El Speculum Naturale escrito por el dominico Vicente de Beauvais hacia la mitad del siglo XIII dice de los sabuesos que son óptimos cazadores aquellos de "orejas largas y caídas", por lo que dicha característica morfológica los distinguía del resto de canes medievales (Beauvais, 1493: 233). Más exhaustiva será la descripción de Alberto Magno, que los describe como canes «de orejas grandes y amplias que cuelgan directamente hacia los maxilares [...] y de labio superior largo y caído y la voz sonora» (Alberto Magno, 2007: 98-99). Se señalan por lo tanto los dos rasgos morfológicos más genuinos de los sabuesos (orejas y belfos), así como sus característicos latidos durante el ejercicio de la caza.

A pesar de ser más o menos homogéneos en su apariencia, los sabuesos recibirán distintos nombres a lo largo de la Baja Edad Media. Vicente de Beauvais los denomina lebreles (leporarius), término empleado generalmente para los galgos, pero que utiliza asimismo para los sabuesos por el hecho de que también se utilizaban para cazar liebres. Sin embargo, Alberto Magno los define como «los perros de caza que no son lebreles», por lo que en el siglo XIII aún carecían de un nombre consensuado. Al igual que Vicente de Beauvais, Li Livres dou Tresor de Brunetto Latini deno- mina lebreles tanto a galgos como a sabuesos. No obstante, de los sabuesos especificará que "otros son lebreles y son llamados sabuesos (segus), porque siguen la presa hasta el final» (Latini, 2007: 304)7. Aunque Latini mantenga el término lebrel para galgos y sabuesos, consideró necesario especificar que los sabuesos en realidad eran llamados «segus». El término segusius de Arriano había sobrevivido en la Baja Edad Media, pero Latini desconoce su origen celta y lo atribuye a la capacidad de los sabuesos de seguir las piezas (del latín sequi). Latini fue un florentino forzado al exilio en Francia en 1260, luego no podemos saber si la palabra «segus» fue utilizada en Francia o Italia para designar a los sabuesos. De hecho, su discípulo Dante Alighieri utilizará el término «bracchetto» para designar a los sabuesos en su rima Sonar bracchetti, e cacciatori aizzare (Alighieri, 2005: 315-317). Braco o brachetus fue un término que en la Edad Media se utilizaba para denominar a distintos perros de caza, pero generalmente a los sabuesos.

El sabueso será también protagonista de los tratados de caza medievales. El primer tratado de caza medieval que hemos conservado recibe el título $D e$ arte bersandi y se compuso en la primera mitad del siglo XIII. Los italianismos del latín de su composición indican que probablemente lo escribió un autor del norte de Italia, que habría transmitido los conocimientos venatorios de un caballero teutónico 
mencionado con el nombre de Guicennas. El tratado está incompleto, pero la mayor parte de los catorce capítulos conservados están dedicados a explicar el entrenamiento de un sabueso atraillado para la caza del ciervo (Anónimo, 1956). En las monterías medievales se hacía uso en un primer momento de un sabueso atraillado para localizar los rastros que el ciervo había dejado durante la noche y saber en qué lugares había de soltarse las jaurías (Cummins, 2003/1988: 3246, 68-83). De arte bersandi es muy minucioso a la hora de explicar cómo entrenar al sabueso desde sus primeras experiencias, puesto que es un aspecto fundamental para poder garantizar el éxito de la montería. Este sabueso atraillado recibe el nombre de brachetus, pero generalmente en la literatura francesa y anglonormanda recibirá el nombre de lymer o limier, mientras que brachet designará a los sabuesos en general (Cummins, 2003/1988: 20-23). Prueba de ello sería el tratado de caza inglés más antiguo conservado: The Craft of Venerie escrito por William Twiti a principios del siglo XIV. En el mismo se designa al sabueso atraillado como lymer frente al resto de sabuesos denominados brachez (Twiti, 1956: 28).

\section{El sabueso en el siglo XIV}

La pintura italiana del siglo XIV representará a los sabuesos con fiel veracidad, por lo que nos resulta fácil hacernos una idea de la morfología que presentaban. Una buena fuente para conocer la morfología de los perros de caza son los diferentes manuscritos del Tacuinum Sanitatis, un cuaderno de salud traducido del árabe al latín que gozó de cierto éxito en la Lombardía del siglo XIV. El cuaderno fue escrito en el siglo XI por un médico cristiano de Bagdad llamado Ibn Butlan. Como su nombre original era Abu al-Hasan es también conocido como Abulkasem de Baldac, dado su origen en la capital del califato abasí. La familia Visconti pudo encargar un manuscrito original iluminado al célebre artista Giovannino de'Grassi, de cuyo modelo conservamos cuatro excelentes copias lombardas de finales del siglo XIV. El Tacuinum Sanitatis advierte de los beneficios y peligros de la ingesta de carne de determinados animales salvajes, estos pasajes están ilustrados en los manuscritos italianos con la caza de dichos animales. Los sabuesos aparecen en la caza de la liebre, el corzo y el jabalí. En las tres miniaturas encontramos

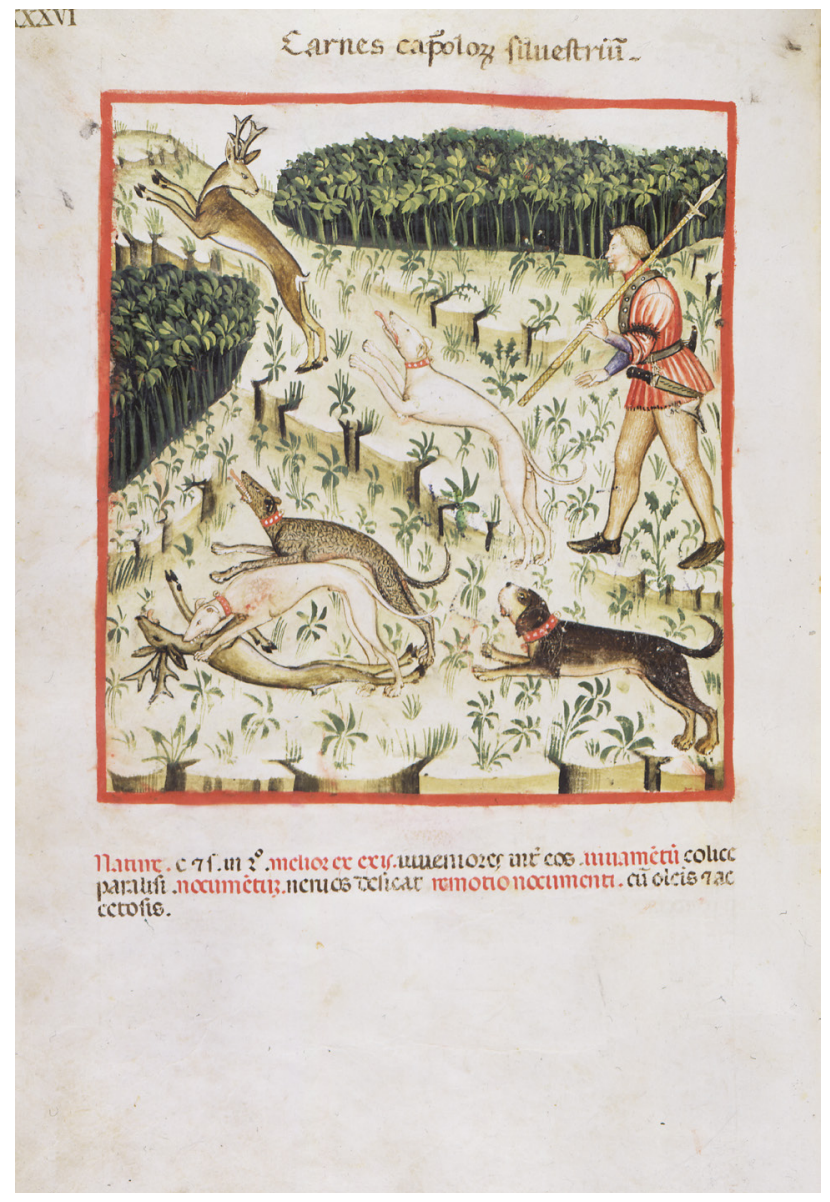

3. Tacuinum (Theatrum) Sanitatis, siglo XIV, Biblioteca Casanatense, Roma, MS 4182, fol. 126r

un solo sabueso con una morfología muy similar, tan solo cambia el color del manto. La caza del corzo presenta un sabueso en la parte inferior latiendo al galope tras haber levantado al menos dos corzos [3]. A la carrera se adelantan los más veloces perros de agarre para poder atrapar al corzo al que el cazador le dará muerte con una lanza. Uno ya ha sido apresado, si bien el más grande huye despavorido ante la amenaza de los alanos. El sabueso de la miniatura de la caza de la liebre se parece bastante al de la caza del corzo, pero si nos atenemos a lo que vemos en la imagen, no se encuentra en una persecución [4]. El sabueso parece estar latiendo el rastro de una liebre encamada en un arbusto cercano. Continuará siguiendo el rastro y latiendo hasta que llegue a la cama y haga saltar a la liebre. Un sabueso es incapaz de atrapar una liebre, para ello hacen falta perros mucho más 


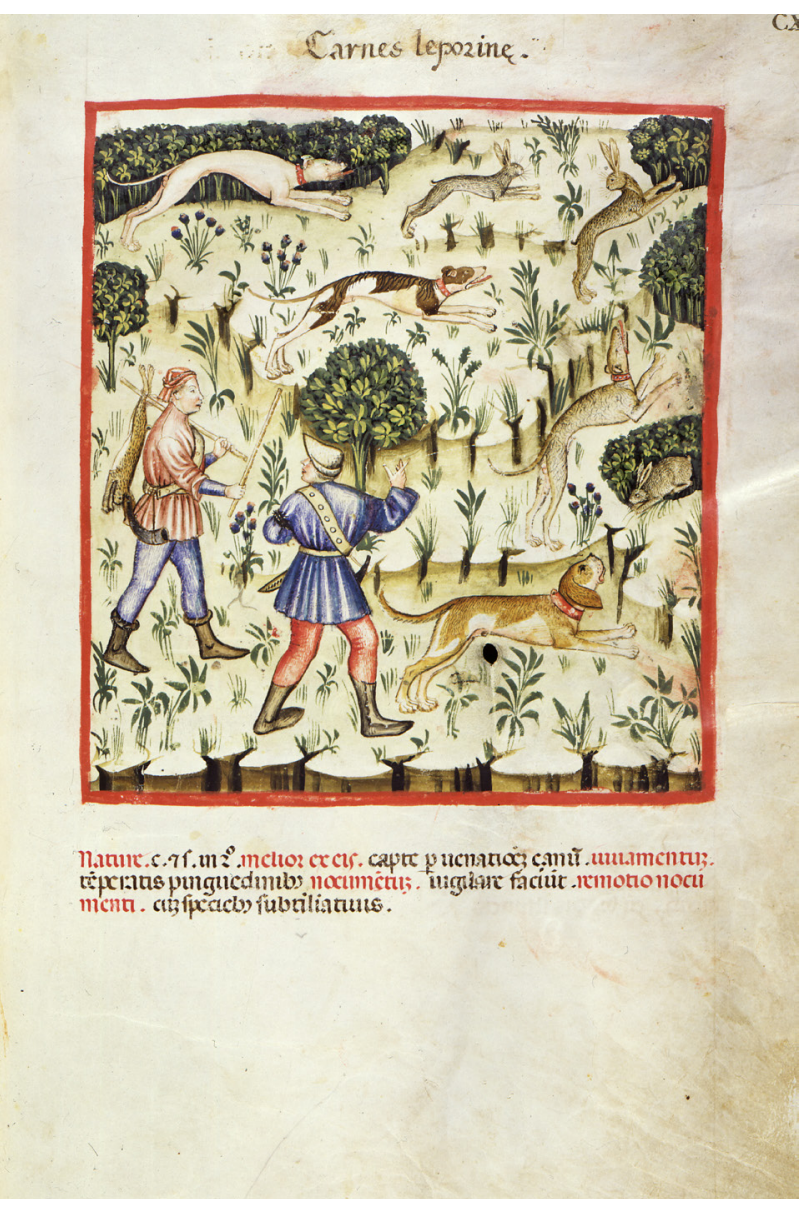

4. Tacuinum (Theatrum) Sanitatis, siglo XIV, Biblioteca Casanatense, Roma, MS 4182, caza de la liebre

veloces que los sabuesos o los alanos, los únicos perros capaces de ganar la carrera de una liebre son los galgos que la persiguen en la parte superior. Dos cazadores observan y comentan la persecución, mientras que uno de ellos porta sobre su espalda una liebre ya cazada colgando de un palo (Morales, 2017: 1022-1028). En ambas escenas los sabuesos son morfológicamente muy distintos a alanos o galgos. Tal y como había señalado Alberto Magno, los sabuesos poseen largas orejas y sus caídos labios cubren la mandíbula.

Una descripción muy detallada de las formas de cazar de los sabuesos y de su morfología la encontramos en el Libro de la montería escrito en el entorno de la realeza castellana entre los siglos XIII y XIV, aunque incorpora pasajes de una traducción castellana de 1252 del tratado árabe Kitab al-yawarih ${ }^{9}$. Se trata de un tratado muy completo que habla fundamentalmente de los sabuesos y los alanos para la caza de animales de gran envergadura. El tratado expone con gran precisión las dificultades que el cazador puede encontrar en la caza del ciervo, el oso o el jabalí y ofrece recomendaciones para atajar estos problemas. Por ejemplo, cuando el bosque sea tan espeso que los monteros no logren entrar en él, el autor aconseja el empleo de sabuesos para levantar un ciervo de la siguiente manera: «deuen soltar aquel can maestro para que lo auya ladrar. Et desde que oyere que lo ladra en cierto, deuen soltar dos canes de los otros, los meiores que touieren; et desde que entendieren que lo ladran todos tres, deuen le dar los otros [canes] que touieren de aquella busca vno a vno". Este pasaje ilustra perfectamente la utilidad de los latidos del sabueso. El cazador no puede entrar en el bosque, pero gracias a los latidos del primer sabueso, sabe dónde ha de soltar a los otros dos. En función de las voces de los canes sabrán dónde y cuándo soltar al resto de la jauría que consiga levantar al venado y darle caza en algún lugar accesible a los monteros. El Libro de la montería describe el ideal morfológico de los sabuesos de la siguiente manera:

\footnotetext{
Primeramente, el sabueso para ser fremoso deue auer estas fechuras: la cabeça quadrada et non aguda de rrostro. Et que aya la nariz un poco tornada arriba. Et sy fuere prieto, que aya la nariz blanca. Et sy fuere blanco, que aya la nariz prieta; que aya las oreias colgadas et non muy grandes, et bien apegadas a la cabeça; et los oios tristes. [...] Et tan bien el sabueso commo la sabuesa que non aya el cabello sedeño ${ }^{10}$.
}

En primer lugar, cuando el escritor habla de que la cabeza ha de ser cuadrada y no aguda de rostro puede querer señalar la diferencia entre un sabueso y un galgo o un podenco de cabeza delgada y hocico afilado. No sabemos muy bien a qué se refiere con la nariz tornada hacia arriba, podría referirse a una convergencia de las líneas cráneo-faciales, deseada hoy en algunos perros de muestra; no obstante, quizás se refiera exclusivamente a la posición de la trufa en el hocico. Por alguna razón puramente estética, el modelo de belleza castellano requería un contraste entre la pigmentación de la trufa y la del manto. Los sabuesos han de tener las orejas colgadas y los ojos tristes, dos de los rasgos que mejor identifican el aspecto de los sabuesos. Un rasgo indeseable en sabuesos y sabuesas es el pelo sedeño, otro as- 


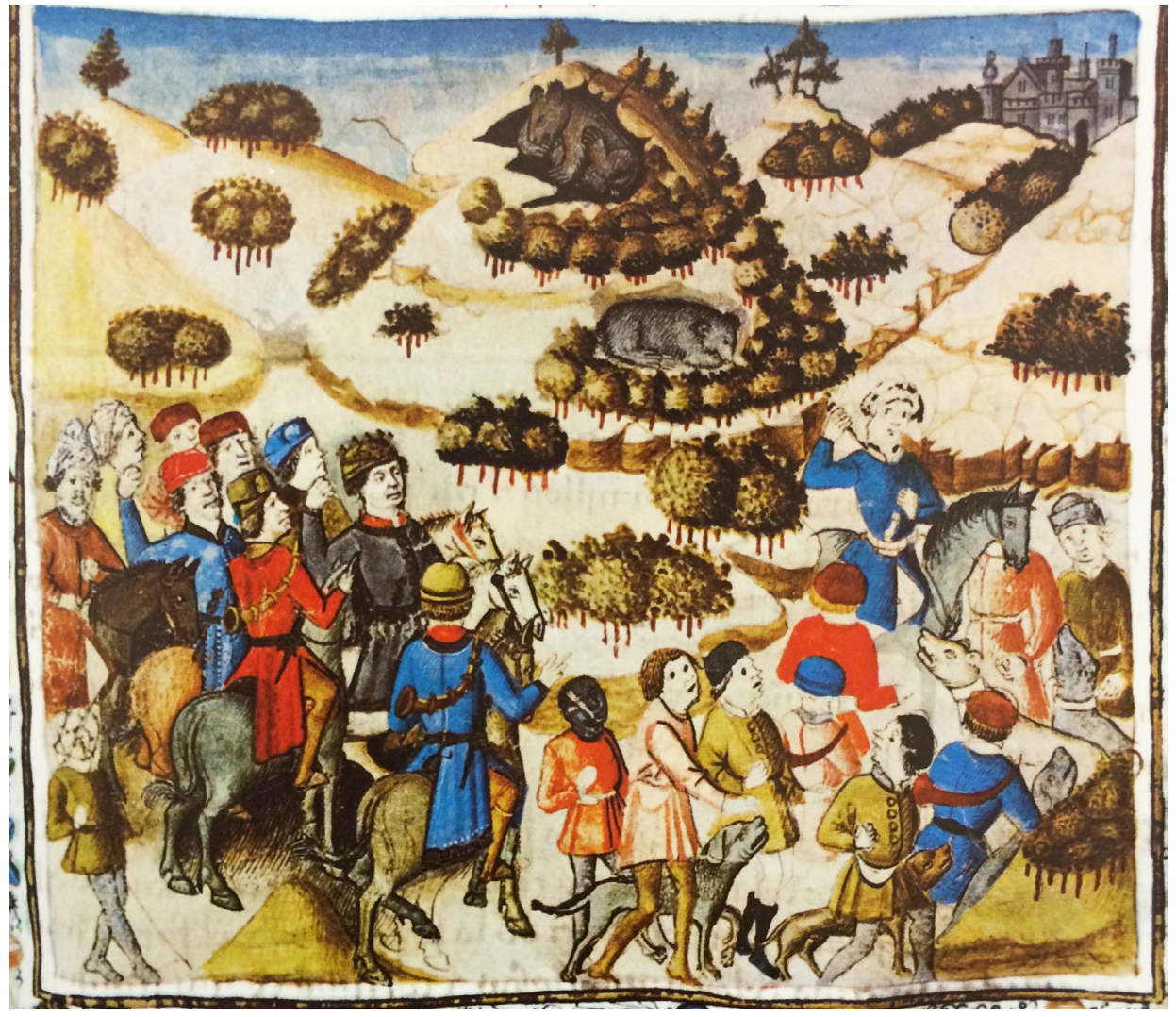

5. Libro de la montería, siglos XIV-XV, Biblioteca del Palacio Real, Madrid, MS II.g.3/2105, fol. 91r

pecto puramente estético que no era del gusto del escritor del Libro de la montería.

Se han conservado varios manuscritos del Libro de la montería desde el siglo XIV, pero solo dos están ilustrados (Van den Abeele, 2013: 18). El más interesante se conserva en el Palacio Real de Madrid (II.g.3/2105), posee seis ricas miniaturas mostrando las cacerías del rey y ha sido datado entre los siglos XIV y XV (López, 1987: 21; Van den Abeele, 2013: 18). En cuatro de las miniaturas encontramos representaciones de sabuesos. La maestría del miniaturista de este códice dista mucho de la del pintor del Tacuinum Sanitatis; no obstante, los sabuesos son claramente reconocibles por sus amplios belfos y largas orejas. Una miniatura ilustra la caza del oso con el rey acompañado de monteros a pie y a caballo [5]. En la parte inferior derecha varios monteros portan sabuesos sujetos con correa, que procederán a soltar para localizar los rastros de los osos que vemos escondidos en la parte superior.
Otra magnífica descripción del sabueso de finales del siglo XIV la encontramos en el Livre de chasse de Gastón Fébus, III Conde de Foix. Su apodo Fébus o Phoebus lo adquirió al compararse con el dios Febo (Apolo) por su hermosura, gallardía y deslumbrante cabellera rubia ${ }^{11}$. El Conde de Foix relata una especie de estándar de belleza morfológico de los sabuesos en estricta relación con la funcionalidad cinegética:

El buen sabueso debe ser grande y grueso de cuerpo y tener las aletas del hocico grandes y abiertas, y un hocico largo y gruesos labios, que cuelguen hacia abajo; los ojos grandes y castaños, o más oscuros; las orejas muy colgantes, anchas y gruesas; el cuello ancho; el pecho ancho; grandes espaldas, patas gruesas y rectas y no demasiado hendidas, pie grande y redondo, con uñas fuertes, los ijares un poco apretados, el vientre estrecho y largo el costillar, la verga pequeña y poco colgante, los testículos pequeños y apretados, buena rabadi- 


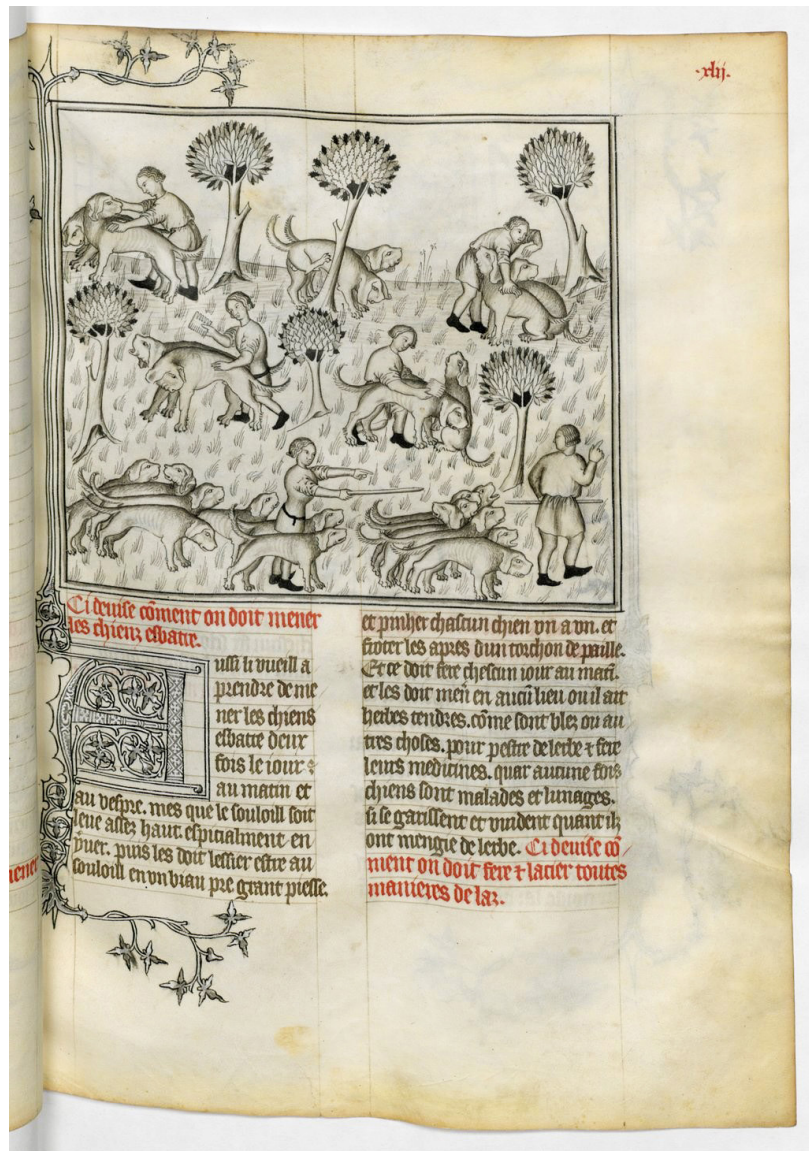

6. Livre de chasse, siglo XIV, Biblioteca Nacional de Francia, París, MS fr. 619, fol. 42r

lla y espinazo fuerte, buenos y gruesos muslos, los corvejones posteriores rectos y no curvados ${ }^{12}$.

El Livre de chasse ofrece asimismo una magnífica descripción del modo de trabajar de los sabuesos. Aunque en ocasiones incorpore material de los bestiarios, la mayor parte del libro está basada en la experiencia directa del autor (McNelis, 1997: 67-76). Fébus retrata sabuesos capaces de olfatear el aire a través del rastro de los animales en la maleza, serían por lo tanto aptos para los bosques y espesuras. Por el contrario, otros sabuesos siguen exclusivamente los rastros sobre la tierra. El perro perfecto es definido por Fébus como el chien baut que «debe ser ardiente y estar siempre dispuesto para cazar; debe ser rápido, correr veloz y largamente, seguir bien a su presa sin desmayo durante todo el día; cazar y acosar bien, correr y gritar con ahínco durante todo el día y olfatear bien». Por los gritos se refiere el Conde de Foix a los latidos, el distintivo ladrido de los sabuesos que permitía saber el tipo de rastro que andaban siguiendo. Fébus continúa explicando diferentes formas de rastrear y latir de estos perros para concluir que la forma más placentera y satisfactoria de cazar es sin duda en compañía de los sabuesos ${ }^{13}$.

El Conde de Foix escribe el Livre de chasse en su madurez, entre 1387 y 1389 cuando ya era un experto cazador. Conservamos al menos cuarenta y seis manuscritos de su obra, lo que indica que gozó de muchísimo éxito. Hacia 1390 se realizaron dos manuscritos en Aviñón ilustrados con ochenta y cinco miniaturas por el artista Jean de Toulouse. Es probable que uno de estos dos manuscritos perteneciese al propio Gastón Fébus, que habría supervisado y participado en el diseño de las miniaturas. Se trata del MS fr. 619 de la Biblioteca Nacional de Francia, caracterizado por poseer miniaturas en grisalla con una atención a los detalles cinegéticos y morfología canina como no encontramos en otros ejemplares (Van den Abeele, 2013: 82-85). Las imágenes ilustran la morfología de los sabuesos, los sabuesos a traílla, siguiendo rastros, en jauría, en persecución, comiendo junto a los monteros, siendo curados de las heridas tras la caza o en los caniles. Una de las imágenes ilustra un pasaje en el que Fébus explica el cuidado diario que han de recibir los perros, consistente en cepillados, sol, paseos y purgas comiendo hierba fresca (Urquijo, 361-362) [6]. La miniatura muestra con feroz naturalismo a los perros saliendo en grupo de los caniles, siendo cepillados u orinando en los árboles. Sus labios y amplias orejas les otorgan un aspecto inconfundible de sabuesos. La copia más conocida del Livre de chasse es la que encarga el duque de Borgoña Juan sin miedo en la primera década del siglo XV, conservado hoy en la Biblioteca Nacional de Francia como MS fr. 616 (Klemettilä, 2015). Nos interesará especialmente la imagen que ilustra el capítulo veintisiete que explica cómo enseñar a los sabuesos a seguir las piezas [7]. Fébus explica que en primer lugar ha de ir un montero con un sabueso atraillado para localizar los rastros; otro cazador esperará con algún compañero y el resto de sabuesos a que el montero del sabueso atraillado le grite para indicarle el lugar desde el que ha de hacer la suelta. La calidad de la miniatura se percibe en las ricas orlas y el fondo dorado. Sobre este fondo se ha representado con todo detalle un frondoso bosque, en el que la 


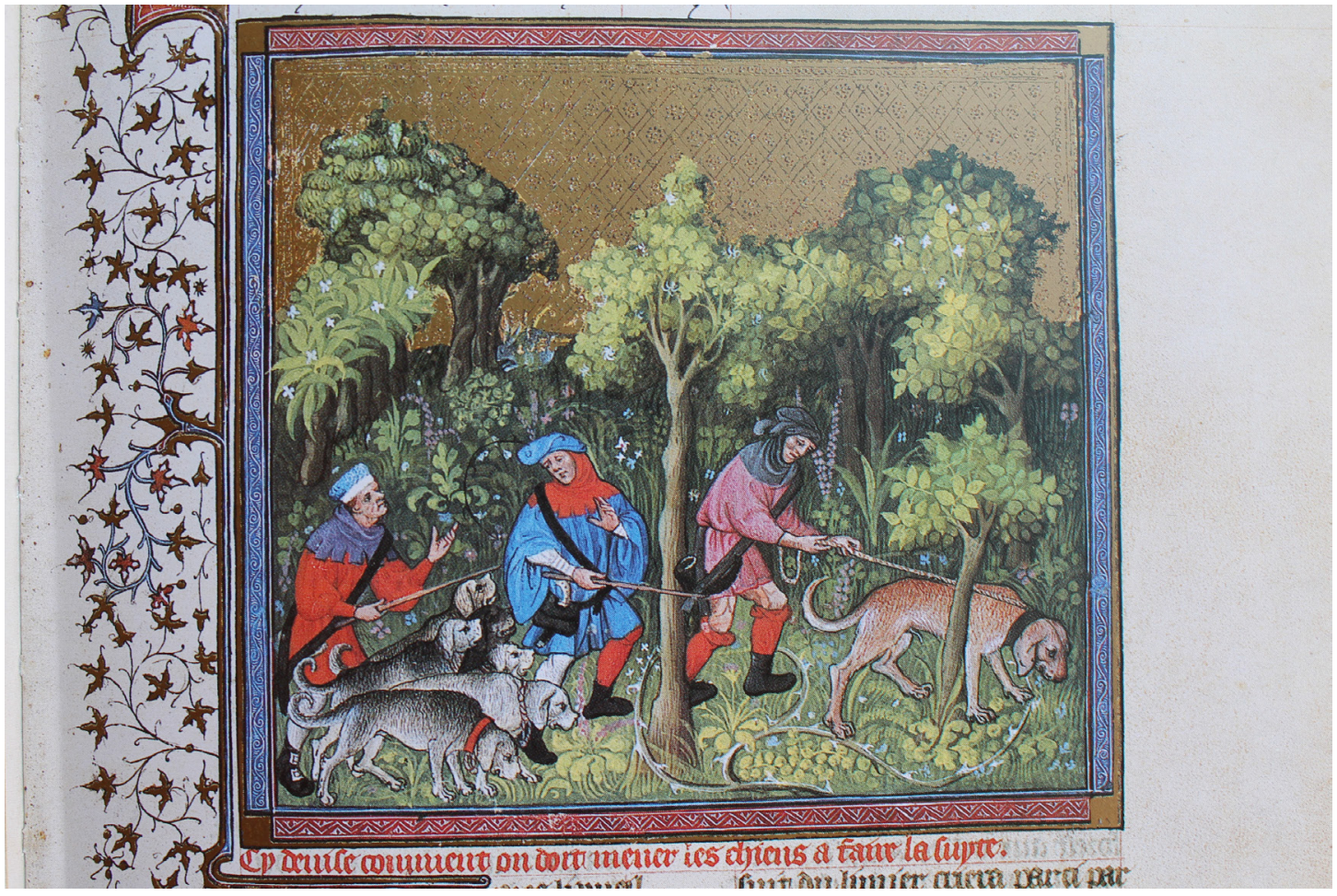

7. Livre de chasse, siglo XIV, Biblioteca Nacional de Francia, París, MS fr. 616, fol. 55r

perspectiva y el volumen se ha logrado magníficamente en la disposición de los árboles. Es el lugar idóneo en el que se encaman los animales y para levantarlos es imprescindible la labor de los sabuesos.

Los sabuesos fueron un privilegio de reyes y nobles para dedicarse al ejercicio de la montería, una afición reser- vada a las clases más privilegiadas por el elevado coste que suponía el mantenimiento de jaurías, caballos o armas de caza. El valor que los hombres más ricos de la Edad Media otorgaron a sus perros de caza nos permite tener una idea clara del papel que jugaron en la conformación de la cultura cortesana y nobiliaria de su época.

\section{Notas}

1 Urquijo (ed.), 1994: 357.

2 El término correcto para definir el ladrido del sabueso mientras sigue el rastro es «latido». En la Baja Edad Media utilizaban los verbos gritar, lamentar, ladrar o aullar para definir el característico sonido de los sabuesos en la caza.

3 En la Baja Edad Media los perros de agarre recibían el nombre de alanos.

4 Thiebaux, 1974: 21-40; Cummins, 1988: 1-11, 32-46; Galloni, 1998: 65-100; Rösener, 2000: 129-150; Almond, 2003: 28-60.

5 Aymard, 1951: 239-240; Hull, 1964; Anderson, 1985; Schnapp, 1997: 177-452; Barringer, 2001.

6 Guardia Pons, 1982: 107-156; Galloni, 1993; Fenske, 1997: 29-93; Bord y Mugg, 2008: 63-71.

7 Esta edición traduce erróneamente levrier por limier.

8 Cogliati Arano, 1976: 10-11; Segre, 2002: 71-75; eadem, 2000: 477-487; Hoeniger, 2006: 51-54.

9 Fradejas, 1992; ídem, 2002; ídem, 2017: 6.

10 El libro de la montería, libro I, caps. ix, xxxviii (Montoya, 1992: 160-161, 214-215).

11 Tilander, 1971: 5-24; Urquijo, 1994: 285-289; Klemettilä, 2015: 48-70. 
12 Para el texto de Fébus en castellano Urquijo, 1994: 354. En versión original Tilander, 1971: 130-131.

13 Carmen Andreu traduce chien baut por perro braco, pero braco es un término con otras implicaciones. Hemos utilizado su traducción, salvo en la palabra crier (gritar), Urquijo, 1994: 132.

\section{Bibliografía}

Fuentes primarias

ALBERTO MAGNO (2007/XIII d. C.), De cane, Loncke, Jeremy (ed.), La practica canum. Le De cane d'Albert le Grand: l'art de soigner les chiens de chasse au Moyen Âge, Laget, París.

ALFONSO XI (1992/XIV d.C.), Libro de la montería, Montoya, Isabel (ed.), Universidad de Granada, Granada.

ALIGHIERI, Dante (2005/XIII d. C.), Rime, De Robertis, Domenico (ed.), Galluzzo, Florencia.

ANÓNIMO (1956/XIII d. C.) Guicennas. De arte bersandi, Tilander, Gunnar ed., Le plus ancient traité de chasse en Occident, Uppsala.

ARRIANO (1999/II d. C.), Cinegética, en PHILIPPS Arthur A. y WILLCOCK, Malcom M. (eds.), Xenophon and Arrian on Hunting with Hounds, Liverpool University Press, Liverpool.

BEAUVAIS, Vicente de (1493/XIII d. C.), Speculum naturale, ed. Hermann Liechtenstein, Venecia.

FÉBUS, Gastón (1971/1387), Livre de la chasse, TILANDER, Gunnar (ed.), Gaston Phoebus. Livre de la chasse, Karlshamn. En castellano URQUIJO, Alfonso de (ed.) (1994), Gaston Phoebus, El libro de la caza, Casariego, Madrid.

JENOFONTE (1965/IV a. C.), Cinegética o Arte de la caza, Mirlo Blanco, Madrid.

LATINI, Brunetto (2007/XIII d. C.), Li Livres dou Tresor, BELTRAMI, Pietro G., SQUILLACIOTI, Paolo, TORRI, Plinio y VATTERONI, Sergio (eds.), Giulio Einaudi, Turín.

TWITI, William (1956/XIV d. C.), La vénerie, TILANDER, Gunnar (ed.), La vénerie de Twiti. Le plus ancienne traité de chasse écrit en Angleterre, Uppsala.

Fuentes secundarias

ALMOND, Richard (2011/2003), Medieval Hunting, The History Press, Stroud.

ANDERSON, J. K. (1985), Hunting in the Ancient World, University of California Press, Berkeley.

AYMARD, Jacques (1951), Les chasses romaines des origines á la fin du siécle des Antonins, E. de Boccard, París.

BARRINGER, Judith M. (2001), The Hunt in Ancient Greece, The Johns Hopkins University Press, Baltimore.

BORD, Lucien-Jean et MUGG, Jean-Pierre (2008), La chasse au moyen âge, Gerfaut, Chartres.

BUGNION, Jacques (2005), Les chasses médiévales. Le brachet, le lévrier, l'épagneul, leur nomenclature, leur métier, leur typologie, Infolio, Gollion.

CAMILLE, Michael (1992), Image on the Edge. The Margins of Medieval Art, Reaktion Books, Londres.

COGLIATI ARANO, Luisa (1976), The Medieval Health Handbook, George Braziller, Nueva York.

CUMMINS, John (2003/1988), The Art of Medieval Hunting. The Hound and the Hawk, Castle Books, Londres.

DURLIAT, Marcel (1979), «La cathédrale St. Étienne de Cahors. Architecture et sculpture. Dixième colloque international de la société française d'archéologie», Bulletin Monumental, n. ${ }^{0}$ 137.4, pp. 285-340.

FENSKE, Lutz (1997), «Jagd und Jäger im früheren Mittelalter. Aspekte ihres Verhältnisses», en RÖSENER, Werner (ed.), Jagd und höfische Kultur im Mittelalter, Vandenhoeck \& Ruprecht, Göttingen.

FRADEJAS RUEDA, José Manuel (1992), «El autor del Libro de la montería: historia y comentario de seis siglos de controversia», en Actas del Il Congreso Internacional de la Asociación Hispánica de Literatura Medieval (Segovia, del 5 al 19 de octubre de 1987), Universidad de Alcalá, Alcalá de Henares, pp. 285-312. 
FRADEJAS RUEDA, José Manuel (2002), «Libro de la montería», en LUCÍA MEGÍAS, José Manuel, ALVAR EZQUERRA, Carlos (eds.), Diccionario filológico de literatura medieval española. Textos y transmisión, Castalia, Madrid, pp. 786-791.

- (2017), «Los libros de la caza medievales y su interés para la historia natural», Arbor. Ciencia, pensamiento y cultura, vol. 193, n. ${ }^{\circ} 786$, octubre-diciembre, pp. 1-10.

GALLONI, Paolo (1993), Il cervo e il lupo. Caccia e cultura nobiliare nel Medioevo, Laterza, Roma.

GUARDIA PONS, Milagros (1982), Las pinturas bajas de la ermita de San Baudelio de Berlanga (Soria), Diputación de Soria, Soria.

HOENIGER, Cathleen (2006), «The Illuminated Tacuinum Sanitatis Manuscripts from Northern Italy, ca. 1380-1400», en GIVENS, Jean A., REEDS, Karen M. y TOUWAIDE, Alain (eds.), Visualizing Medieval Medicine and Natural History, 1200-1550, Ashgate, Londres, pp. 51-54.

HULL, Denison B. (1964), Hounds and Hunting in Ancient Greece, The University of Chicago Press, Chicago.

KENAAN-KEDAR, Nurith (1995), Marginal Sculpture in Medieval France. Towards the Deciphering of an Enigmatic Pictorial Language, Scholar Press, Aldershot.

KLEMETTILÄ, Hanele (2015), Animals and Hunters in the Late Middle Ages. Evidence from the BnF MS fr. 616 of the Livre de chasse by Gaston Fébus, Routledge, Nueva York y Londres.

LÓPEZ SERRANO, Matilde (1987), Libro de la montería del rey de Castilla Alfonso XI, Patrimonio Nacional, Madrid.

McNELIS, James (1997), «A Greyhound should have 'eres in the manere of a serpent'. Bestiary Material in the Hunting Manuals Livre de chasse and The Master of Game», en HOWEN, L. A. J. R., Animals and the Symbolic in Mediaeval Art and Literature, Egbert Forsten, Groninga, pp. 67-76.

MORALES MUÑIZ, Dolores Carmen (2017), «Los lepóridos en la economía y la cultura de los siglos medievales: dieta, caza e iconografía», Estudios sobre patrimonio, cultura y ciencias medievales, n. ${ }^{\circ}$ 19, pp. 1009-1042.

RÖSENER, Werner (2000), «Adel und Jagd. Die Bedeutung der Jagd im Kontext der adeligen Mentalität», en PARAVACINI BAGLIANI, Agostino, VAN DEN ABEELE, Baudouin (eds.), La chasse au Moyen Âge. Société, traités, symboles, Sismel, Florencia, pp. 129-150.

SCHNAPP, Alain (1997), Le chasseur et la cité. Chasse et érotique dans la Grèce ancienne, Albin Michel, París.

SEGRE RUTZ, Vera (2002), Historia Plantarum. Erbe, oro e medicina nei codici medievali, Franco Cosimo Panini, Modena.

- (2000), «Lo studio del vero del mondo animale nella bottega trecentesca di Giovannino de’ Grassi», en Micrologus VII. II mondo animale, Sismel, Florencia, pp. 477-487.

THIÉBAUX, Marcelle (1974), The Stag of Love. The Chase in Medieval Literature, Cornell University Press, Ithaca y Londres.

VAN DEN ABEELE, Baudouin (2013), Texte et image dans les manuscrits de chasse médiévaux, Bibliothèque Nationale de France, París. 